\title{
Vacuum ultraviolet photoionization and ionic fragmentation of the isoxazole molecules
}

Tomasz J. Wasowicz ${ }^{1, *}$, Antti Kivimäki ${ }^{2,3}$, Daniele Catone ${ }^{4}$, Robert Richter ${ }^{5}$

${ }^{1}$ Department of Physics of Electronic Phenomena, Gdańsk University of Technology, ul. G. Narutowicza 11/12, 80-233 Gdańsk, Poland

${ }^{2}$ Nano and Molecular Systems Research Unit, University of Oulu, P.O. Box 3000, 90014 Oulu, Finland

${ }^{3}$ MAX IV Laboratory, Lund University, P.O. Box 118, 22100 Lund, Lund Sweden ${ }^{4}$ CNR-ISM, Division of Ultrafast Processes in Materials (FLASHit), Area Della Ricerca di Roma 2 Tor Vergata, Via del Fosso del Cavaliere 100, 00133 Rome, Italy ${ }^{5}$ Elettra - Sincrotrone Trieste, Area Science Park Basovizza, 34149 Trieste, Italy *Corresponding author: tomasz.wasowicz1@pg.edu.pl; twasowicz@mif.pg.gda.pl

\begin{abstract}
The photofragmentation of the isoxazole molecules producing ionized atomic and molecular fragments was investigated in the photon energy range of 9-32 eV, using synchrotron radiation excitation combined with ion time-of-flight spectrometry. Twenty-one well resolved cations were identified in the mass spectra of the isoxazole, and their appearance energies were determined. The yield curves of these cations were obtained in the photon energy ranges from their appearance energies up to $32 \mathrm{eV}$. Moreover, the total ion yield of isoxazole was recorded with high precision in the photon energy range of 9.9-10.5 eV. This allowed the determination of the adiabatic ionization energy of $9.96(0.02) \mathrm{eV}$ in excellent agreement with earlier spectroscopic studies. Our results show that the dissociative ionization of isoxazole starts from the ring-opening and isomerization of isoxazole, and further it follows strictly through its ionic states. Possible ionic fragmentation channels yielding particular ions are discussed.
\end{abstract}

\section{Introduction}


Cancer diseases are important public health anxiety worldwide because they result in millions of deaths every year. Standard cure routines for abnormal malignant cells are surgery, and nowadays also radiotherapy or hadrontherapy. Unlike surgical treatment, the interaction of radiation with biomolecules is still not understood well despite its importance in medical therapies. Thus, intense studies are currently undertaken to explore alterations induced by different types of radiation in biological units of living organisms, particularly the DNA molecules [1]. It is generally accepted that primary ionizing beams and secondary particles endanger the DNA and RNA structures by producing bond breaks in their building blocks [2]. The examination of the most fragile bonds of the backbone molecules of the RNA and the DNA helix (deoxyribose sugar, nitrogen bases, and their analogs) caused by impact with different kinds of radiation offers a useful guide to understand better from a fundamental perspective physicochemical modifications that damage more complex biologically relevant molecules. Nitrogen-containing heterocyclic molecules occur widely in biological systems and are often used as prototypical ring structures in such investigations [3]. Probing the mechanisms of the photoexcitation, relaxation, and fragmentation of these molecules is thus advantageous to obtain a full picture of processes occurring at the molecular level. These results may later be used to improve radio-therapeutical protocols and to enhance medicinal engineering proficiency [4], [5].

Isoxazole $\left(\mathrm{C}_{3} \mathrm{H}_{3} \mathrm{NO}\right.$, see Figure 1) is one of the vital five-membered heterocyclic aromatic compounds that provides a structural unit for many organic and biologically active substances. For instance, it is a building unit of some agrochemical (herbicidal, insecticidal) compounds [6]. The isoxazole ring serves as an essential structural unit in designing analgesic, anti-inflammatory, anticancer, antimicrobial, antiviral, anticonvulsant, and immunosuppressant drugs [7], [8], [9]. It may also serve as a simple analog of building blocks of DNA, the nucleotides, in the investigations of the interaction between ionizing radiation and biological material. Indeed, adenine and guanine contain nitrogen atoms in their fivemembered molecular subrings. The broad spectrum of biological activities and therapeutic potential of isoxazole is related to its unique ring structure that consists of one oxygen atom 
and one nitrogen atom at adjacent positions (see Figure 1). The $\mathrm{O}$ and $\mathrm{N}$ atoms are connected by a very weak bond, the $\mathrm{N}(2)=\mathrm{C}(3)$ bond length is shorter than the $\mathrm{C}(4)=\mathrm{C}(5)$ bond length [10], [11], [12]. This ring has the properties of an aromatic system with a fully conjugated set of $\pi$-electrons, the two highest occupied orbitals being $\pi_{2}$ and $\pi_{3}$. The outermost occupied molecular orbitals of isoxazole in the $\mathrm{X}^{1} \mathrm{~A}^{\prime}$ ground state are $\left(11 a^{\prime}\right)^{2}\left(1 a^{\prime \prime}\right)^{2}\left(12 a^{\prime}\right)^{2}\left(13 a^{\prime}\right)^{2}\left(14 a^{\prime}\right)^{2}\left(15 a^{\prime}\right)^{2}\left(2 a^{\prime \prime}\right)^{2}\left(3 a^{\prime \prime}\right)^{2}[11]$, [12], [13]. The 15a' orbital is the $\sigma$ nitrogen lone pair $\left(\mathrm{LP}_{\mathrm{N}}\right)$ and the 1a", 2a", and $3 \mathrm{a}$ " orbitals are labeled $\pi_{1}, \pi_{2}$, and $\pi_{3}$, respectively.

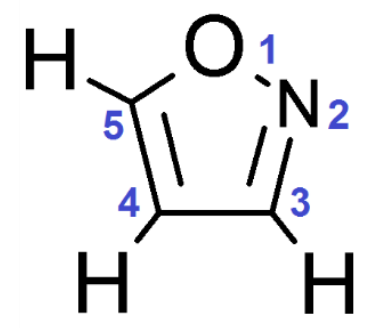

Figure 1. Schematic diagram of the isoxazole molecule, $\mathrm{C}_{3} \mathrm{H}_{3} \mathrm{NO}$, showing labeling of the atoms.

Taking into account the relevance of the isoxazole molecule in many different fields of chemistry, biology, and medicine, it is important to understand the mechanisms leading to its disintegration. However, there is a limited amount of work performed on the fragmentation processes of isoxazole in the gas phase. The earliest studies of Bouchoux and Hoppilliard [14] focused on the dissociative ionization processes of isoxazole caused by electron impact. Apart from the parent cation their mass-resolved ion spectra revealed the following fragment ions: $\mathrm{C}_{3} \mathrm{H}_{2} \mathrm{NO}^{+}$(formed by loss of an $\mathrm{H}$ atom), $\mathrm{C}_{2} \mathrm{H}_{3} \mathrm{~N}^{+}$(resulting from loss of a CO molecule) and $\mathrm{C}_{2} \mathrm{H}_{2} \mathrm{~N}^{+}$(obtained from loss of $\mathrm{HCO}$ ), $\mathrm{HCO}^{+}$(obtained in diverse reactions), and $\mathrm{C}_{2} \mathrm{H}_{2} \mathrm{O}^{+}$ (after detachment of $\mathrm{HCN}$ ). Based on theoretical calculations, they suggested that the dissociation of the isoxazole parent cation starts from the ring-opening by cleavage of the $\mathrm{N}-$ $\mathrm{O}$ bond and the migrations of $\mathrm{H}$ atoms.

In the next two decades, the kinetics of neutral isoxazole thermal unimolecular decomposition was investigated. In the pyrolytic studies of isoxazole, the single-pulse shock 
tube technique operating in the temperature range of 850-1100 K [15] and the flash vacuum pyrolysis in the range of 620-1170 K [16] were exploited. These investigations showed that the major pairs of products in isoxazole pyrolysis are carbon monoxide $(\mathrm{CO})$ and acetonitrile $\left(\mathrm{CH}_{3} \mathrm{C} \equiv \mathrm{N}\right)$, and hydrogen cyanide $(\mathrm{HCN})$ and ketene $\left(\mathrm{H}_{2} \mathrm{C}=\mathrm{C}=\mathrm{O}\right)$, followed by small fractions of acrylonitrile $\left(\mathrm{C}_{3} \mathrm{H}_{3} \mathrm{~N}\right)$, propionitrile $\left(\mathrm{C}_{3} \mathrm{H}_{5} \mathrm{~N}\right)$, and acetylene $\left(\mathrm{C}_{2} \mathrm{H}_{2}\right)$ [15], [16]. Lifshitz and Wohlfeiler [15] suggested additionally that the decomposition mechanism involves the $\mathrm{N}-\mathrm{O}$ bond rupture, followed by the $\mathrm{H}$ atom transfer from $\mathrm{C}(5)$ to $\mathrm{C}(4)$, and further scission of the single bond between these carbon atoms. The quantum chemical theoretical calculations of unimolecular decomposition channels of isoxazole supported these interpretations [17], [18], [19]. In particular, the calculations indicated that the isoxazole molecule might be subject to concerted isomerization processes before decomposition. The major one involves the opening of the isoxazole ring by breaking of the weakest $\mathrm{N}(2)-\mathrm{O}(1)$ bond to form a stable linear nitrile $\mathrm{N} \equiv \mathrm{CCH}_{2} \mathrm{CHO}$ isomer. In this structure, the $\mathrm{C}=\mathrm{O}$ double and $\mathrm{N} \equiv \mathrm{C}$ triple bonds are formed, accompanied by the hydrogen migration from the $\mathrm{C}(3)$ atom to the $\mathrm{C}(4)$ atom. $\mathrm{N} \equiv \mathrm{CCH}_{2} \mathrm{CHO}$ becomes then an intermediate that may experience further rearrangement in fragmentation into acetonitrile, $\mathrm{CH}_{3} \mathrm{C} \equiv \mathrm{N}+\mathrm{CO}$, or ketenimine, $\mathrm{H}_{2} \mathrm{C}=\mathrm{C}=\mathrm{NH}+\mathrm{CO}$. The pyrolysis of isoxazole was recently re-examined by Nunes et al. [20] who utilized high-pressure pulsed pyrolysis in a $15 \mathrm{~K}$ argon matrix and analyzed the isolated products using infrared vibrational spectroscopy. In contrast to the aforementioned shock tube experiments, they observed ketenimine $\mathrm{H}_{2} \mathrm{C}=\mathrm{C}=\mathrm{NH}+\mathrm{CO}$, and isomerization of isoxazole to 3-hydroxypropenenitrile, $\mathrm{HOCH}_{2} \mathrm{CH}_{2} \mathrm{CN}$. To elucidate these results, Nunes et al. [20] additionally performed computational studies. On the one hand, they showed that the formation of the $\beta$-formylvinylnitrenes in an open-shell singlet state is a starting point in lowtemperature thermal decomposition and, on the other hand, they pointed out the importance of other mechanisms, including direct cleavage reactions and $\mathrm{H}$ atom migrations, which under high-temperature conditions give rise to the formation of different products [20].

The most recent photodissociation experiments [21], [22], [23], [24] shed more light on the underlying physics of fragmentation mechanisms of isoxazole molecule. In the studies 
of the vacuum-ultraviolet photodissociation of neutral isoxazole in the energy range of 14-50 eV, Wasowicz et al. [21], [22] exploited photon-induced fluorescence spectroscopy to identify the dissociation products by detecting their fluorescence emission. In particular, their investigations showed [21], [22] that the photofragmentation of isoxazole in the valence region can proceed via excitation to higher-lying superexcited Rydberg states, which then decay into two-, three-, or even four-fragment channels producing excited hydrogen atoms $\mathrm{H}(n)$ as well as vibrationally and rotationally excited diatomic $\mathrm{CH}\left(\mathrm{A}^{2} \Delta\right), \mathrm{CH}\left(\mathrm{B}^{2} \Sigma^{-}\right)$, $\mathrm{CN}\left(\mathrm{B}^{2} \Sigma^{+}\right), \mathrm{C}_{2}\left(\mathrm{~d}^{3} \Pi_{\mathrm{g}}\right)$, and $\mathrm{NH}\left(\mathrm{A}^{3} \Pi\right)$ fragments. Moreover, their theoretical calculations revealed the critical role of the $\mathrm{N}-\mathrm{O}$ ring-opening and hydrogen migration mechanism in the formation of the $\mathrm{NH}$ fragment, which is not a self-contained unit in the structure of isoxazole [22]. At the same time, Nunes et al. [23] reported studies on the photochemistry of matrixisolated isoxazole triggered by low-energy narrowband tunable UV laser light, accompanied by the Multireference Configuration Interaction with Singles and Doubles (MRCISD)/ccpVTZ calculations. Upon irradiation at $240 \mathrm{~nm}(5.17 \mathrm{eV})$, the ketene and hydrogen cyanide were detected [23]. When the laser energy was increased to $5.61 \mathrm{eV}(\lambda=221 \mathrm{~nm})$, the five isomeric forms of isoxazole, i.e., 2-formyl-2H-azirine, 3-formylketenimine, 3hydroxypropenenitrile, imidoylketene, and 3-oxopropanenitrile, were formed in addition to those fragments [23]. Nunes et al. [23] also performed quantum chemical computations and, based on them, pointed out that the formation of $\beta$-formylvinylnitrenes in the open-shell singlet state can play a fundamental role in the photodissociation mechanism [23]. The calculations of Cao [25] established that below the first ionization potential, the $\mathrm{N}-\mathrm{O}$ bond scission in isoxazole occurs ultrafast along the two lowest-lying excited states $\mathrm{S}_{1}\left({ }^{1} \pi \pi^{*}\right)$ and $\mathrm{S}_{2}\left({ }^{1} \mathrm{n}_{\mathrm{N}} \pi^{*}\right)$. These reactions open two decomposition channels, namely, the isomerization to 2formyl-2H-azirine and 3-formylketenimine that further dissociate to $\mathrm{HCN}+\mathrm{CHCHO}$ diradical and to $\mathrm{HCO}+\mathrm{CHCHN}$ diradical, respectively [25]. The key role of the singlet vinylnitrenes production in the low energy photoreactions of isoxazole was additionally confirmed [25]. The most recent experimental investigation on the fragmentation pathways of isoxazole was performed by Dias et al. [24], who observed photodissociation in the UV using 
a chirped-pulse Fourier transform mm-wave spectroscopy in a pulsed uniform flow. Upon irradiation at $193 \mathrm{~nm}(6.42 \mathrm{eV}), \mathrm{HCN}$ and $\mathrm{CH}_{3} \mathrm{CO}$ were the predominant dissociation products detected with the branching ratios 53.8 and $23.4 \%$, respectively [24]. A few fragments with branching fractions below $10 \%$, namely $\mathrm{HCO}, \mathrm{CH}_{2} \mathrm{CN}, \mathrm{CH}_{2} \mathrm{CO}, \mathrm{HCCCN}$, $\mathrm{HCN}$, and HNC were also recorded [24]. Based on previous calculations, it was suggested [24] that the observed relative branching ratios can be only explained when the proper contribution of the direct or indirect ultrafast photodissociation processes are considered.

For the sake of completeness, we also mention electron-induced fragmentation studies of neutral isoxazole. Linert et al. [26] measured the excited hydrogen atoms $\mathrm{H}(n)$ and the vibrationally and rotationally excited diatomic fragments $\mathrm{CH}\left(A^{2} \Delta\right), \mathrm{CN}\left(B^{2} \Sigma^{+}\right)$, and $\mathrm{C}_{2}\left(d^{3} \Pi_{\mathrm{g}}\right)$ using the optical excitation technique in the electron-impact energy range of $10-85 \mathrm{eV}$. They suggested that the fragmentation proceeds via the opening of the isoxazole ring into the linear nitrile isomer, $\mathrm{N} \equiv \mathrm{CCH} 2 \mathrm{HC}=\mathrm{O}$, which further dissociates yielding excited fragments, which may have kinetic energies up to a few electron volts [26]. Recently, Li et al. [27] investigated dissociative electron attachment (DEA) to isoxazole using crossed electron/molecular beams experiments with mass spectrometric detection of the anions. They found [27] that the most dominant fragmentation pathway is initiated by the lowest $\pi^{*}$ shape resonance state and occurs via the hydrogen loss at site 3 .

To the best of our knowledge, VUV-photon-induced ionization and ionic fragmentation of isoxazole has not been reported in the literature. The current study aims to unravel the dissociation processes in isoxazole, which lead to the formation of ionic products in the photon energy range of 9-32 eV, using ion time-of-flight (TOF) spectrometry combined with the photoelectron-photoion coincidence (PEPICO) technique [28]. This technique allowed us to measure the total yield and TOF mass spectra of the produced ions. The latter displays the production of a great number of the cations. The yield curves of the identified fragments were obtained by recording the mass spectra as a function of the incident photon energy. From the experimental data we also determined the appearance energies of particular cations and compared them with the results of the previous electron impact studies. 
The fragments described here differ from those reported previously and their observation gives a new insight into the dissociative photoionization channels in isoxazole molecule. The possible fragmentation mechanisms are elucidated.

\section{Experiment}

The measurements were carried out at the Circular Polarization (CiPo) beamline [29] of the Elettra synchrotron radiation storage ring in Trieste, Italy. The CiPo beamline supplies radiation from an electromagnetic elliptical undulator/wiggler and is equipped with a Normal Incidence Monochromator for low photon energies $(5-35 \mathrm{eV})$. The used undulator mode produced linearly polarized radiation, which was dispersed in the energy range $9-35 \mathrm{eV}$ by two different gratings: an aluminum holographic spherical grating with 1200 grooves $\mathrm{mm}^{-1}$ (Al-NIM) used to cover the 5-16 eV energy range and a gold holographic spherical grating with 2400 grooves $\mathrm{mm}^{-1}$ (Au-NIM) used to cover the $16-35 \mathrm{eV}$ energy range. The photon energy was calibrated by observing the valence excitations in noble gases.

We used the experimental apparatus described by Kivimäki et al. [28]. It consists of a modified Wiley-McLaren time-of-flight (TOF) spectrometer, which was originally used to detect photoelectron-photoion coincidences and subsequently also neutral-particle-photoion coincidences [30]. The setup in the modified configuration can also be used to measure PEPICO spectra. The TOF spectrometer (with a 203-mm long drift tube) was oriented parallel to the electric vector of the linearly polarized synchrotron light. In the interaction region, the monochromatic photon beam from the beamline crossed the effusive beam of the sample molecules emanating from a hypodermic needle [31]. The ambient pressure in the experimental chamber was $2.5-8.5 \times 10^{-7}$ mbar during the measurements, but it was estimated to be 10-30 times higher in the interaction region. The base pressure in the chamber was $\sim 8 \times 10^{-8}$ mbar. When synchrotron light interacts with studied molecules, some of them are ionized and further dissociate into ionic and neutral fragments. Resulting positive ions were 
pushed toward the acceleration region and entered a drift tube, and were detected by a microchannel plate (MCP) detector. The flight times of the positive ions in the TOF spectrometer were used to determine the masses of the original fragments, and consequently to identify them.

In order to identify the fragmentation processes and their products, the time-of-flight mass spectrum of isoxazole was first measured with good statistics at the fixed photon energy of $32 \mathrm{eV}$ with Au-NIM. The total acquisition time was 260 minutes. Second, the total ion yield (TIY) was recorded over the photon energy range of 9.85-10.80 eV with Al-NIM. The photoionization efficiency curves of the identified fragment ions, shortly called "the cation yield curves" in this paper, were then obtained by recording the mass spectra as a function of the incident photon energy. Measurements were carried out in the photon energy range from the respective thresholds up to $32 \mathrm{eV}$ with an energy step of $20 \mathrm{meV}$ below $22 \mathrm{eV}$, and 500 $\mathrm{meV}$ in the 22-32 energy range. In order to avoid a small contribution of the second-order light occurring below $15 \mathrm{eV}$, the measurements in different energy regions were performed exploiting different approaches. In the energy range of 9.5-11 eV, a LiF filter with Al-NIM was used to cut off the higher-order light. This filter was also inserted in the beamline during the acquisition of the total ion yield. In the energy range of 11-16 eV, a correction function for the data was derived by comparing the argon ion yield with the argon photoionization crosssection [32]. The contribution of the second-order light in the exciting radiation of the CiPo beamline in the photon energy range above $15 \mathrm{eV}$ was calculated to be below $1 \%$ [29], and therefore data collection above $16 \mathrm{eV}$ was performed without any filters or correction curves. The complete cation yield curves consist of four scans measured in the consecutive energy regions. To provide a complete cationic yield, the scans were matched with each other after normalization to measuring time, incident photon flux, and the Ar correction function if necessary. The incident photon flux was measured with a neutral Au mesh located before the experimental chamber. The background of each mass peak was taken to be the average of the intensities below and above the group of peaks to which the peak belonged and was subtracted from the corresponding peak intensity. 
The sample of isoxazole was purchased from Sigma-Aldrich with a stated purity of 99\%. Isoxazole is liquid at room temperature, and it was subjected to several freeze-pumpthaw cycles to eliminate all traces of contaminating gases. Despite that, some residual air and water impurities were identified by the detection of $\mathrm{O}_{2}{ }^{+}(\mathrm{m} / \mathrm{z}=32)$ and $\mathrm{H}_{2} \mathrm{O}^{+}(\mathrm{m} / \mathrm{z}=18)$ peaks. The intensities of $\mathrm{O}_{2}{ }^{+}$and $\mathrm{H}_{2} \mathrm{O}^{+}$did not exceed $1 \%$ and $4 \%$, respectively, of the highest peak intensity at $32 \mathrm{eV}$. Therefore, the intensities of $\mathrm{m} / \mathrm{z}=28$ fragments were corrected for a possible contribution from $\mathrm{N}_{2}{ }^{+}$(due to a leak in the gas inlet system) using the $\mathrm{O}_{2}{ }^{+}$peak as a reference and the ratio $\mathrm{O}_{2} / \mathrm{N}_{2}=1 / 4$ [33], for energies above the formation threshold of $\mathrm{N}_{2}{ }^{+}$, i.e., $15.581(8) \mathrm{eV}[34]$.

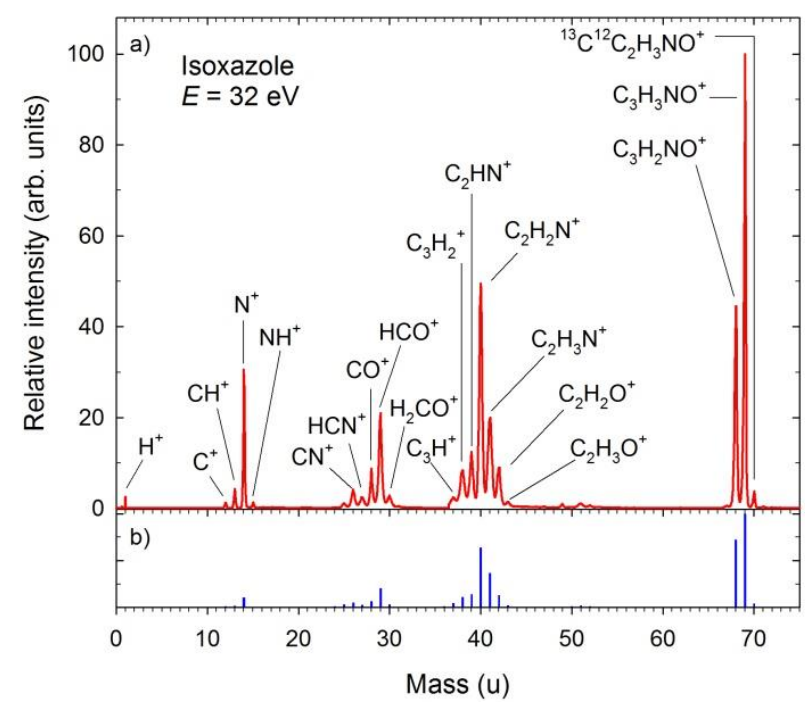

Figure 2. a) The normalized mass spectrum of the cations of isoxazole measured at the photon energy of $32 \mathrm{eV} . \mathrm{b})$ The cations distribution obtained in the electron-impact ionization of isoxazole [35].

\section{Results and discussion}

\subsection{Mass spectrum of isoxazole}

The normalized mass spectrum of isoxazole measured at the photon energy of $32 \mathrm{eV}$ is presented in Figure 2a, together with the tentative assignments of the mass peaks. The assignments were made for the most abundant isotopes. The relative abundances of the cations obtained from the peak intensities are listed in Table 1. These relative abundances 
may contain small contributions from intensities of lower-lying peaks due to the appearance of heavier isotopes in the natural composition of individual elements. The cationic distribution after electron-impact ionization of isoxazole from the NIST database [35] is shown in Figure $2 \mathrm{~b}$ for comparison. The present mass spectrum is in good overall agreement with that published in the NIST database [35]. In both the spectra, the mass peaks form four groups separated well from each other on the mass scale. In the present mass spectrum, there is a new group of very weak peaks at $\mathrm{m} / \mathrm{z}=49-52$ that did not arise from fragmentation of isoxazole. Those fragments originated from the dissociative ionization of residual methylene chloride, a well-known substance commonly used in the synthesis of isoxazole molecule. It is of note that the intensities of methylene chloride fragments do not affect the isoxazole mass spectrum.

Table 1. The most probable assignments and relative intensities ( $\left.I_{\text {Rel }}\right)$ (in \%) of cations observed from isoxazole at the photon energy of $32 \mathrm{eV}$. Possible neutral fragmentation products are also given.

\begin{tabular}{|l|l|l|l|}
\hline M & Cation & $I_{\text {Rel }}$ at $E=$ & Possible neutral products \\
$(\mathrm{u})$ & assignment & $32 \mathrm{eV}$ & \\
\hline 70 & $\mathbf{1 3}^{\mathbf{2}} \mathbf{C}_{2} \mathbf{H}_{3} \mathbf{N O}^{+}$ & 3.76 & \\
\hline 69 & $\mathbf{C}_{3} \mathbf{H}_{3} \mathbf{N O}^{+}$ & 100.00 & \\
\hline 68 & $\mathbf{C}_{3} \mathbf{H}_{2} \mathbf{N O}^{+}$ & 44.56 & $\mathrm{H}$ \\
\hline 43 & $\mathbf{C}_{2} \mathbf{H}_{3} \mathbf{O}^{+}$ & 1.43 & $\mathrm{CN}$ \\
\hline 42 & $\mathbf{C}_{2} \mathbf{H}_{2} \mathbf{O}^{+}$ & 9.09 & $\mathrm{HCN} ; \mathrm{H}+\mathrm{CN}$ \\
\hline 41 & $\mathbf{C}_{2} \mathbf{H}_{3} \mathbf{N}^{+}$ & 20.12 & $\mathrm{CO}$ \\
\hline 40 & $\mathbf{C}_{2} \mathbf{H}_{2} \mathbf{N}^{+}$ & 49.69 & $\mathrm{CHO} ; \mathrm{H}+\mathrm{CO}$ \\
\hline 39 & $\mathbf{C}_{2} \mathbf{H N}^{+}$ & 12.45 & $\mathrm{H} 2 \mathrm{CO} ; \mathrm{HCO}+\mathrm{H}$ \\
\hline 38 & $\mathbf{C}_{3} \mathbf{H}_{2}{ }^{+}$ & 8.59 & $\mathrm{HNO} ; \mathrm{H}+\mathrm{NO}$ \\
\hline 37 & $\mathbf{C}_{3} \mathbf{H}^{+}$ & 2.42 & $\mathrm{HNOH} ; \mathrm{H}+\mathrm{NO}$ \\
\hline 30 & $\mathbf{H}_{2} \mathbf{C O}^{+}$ & 2.98 & $\mathrm{C}_{2} \mathrm{HN} ; \mathrm{CN}+\mathrm{CH}$ \\
\hline
\end{tabular}




\begin{tabular}{|l|l|l|l|}
\hline 29 & $\mathbf{H C O}^{+}$ & 20.75 & $\mathrm{C}_{2} \mathrm{H}_{2} \mathrm{~N}$ \\
\hline 28 & $\mathbf{C O}^{+}$ & 8.80 & $\mathrm{C}_{2} \mathrm{H}_{3} \mathrm{~N}$ \\
\hline 27 & $\mathbf{H C N}^{+}$ & 5.55 & $\mathrm{C}_{2} \mathrm{H}_{2} \mathrm{O}$ \\
\hline 26 & $\mathbf{C N}^{+}$ & 4.13 & $\mathrm{C}_{2} \mathrm{H}_{3} \mathrm{O} ; \mathrm{HCO}+\mathrm{CH}+\mathrm{H}$ \\
\hline 25 & $\mathbf{C}_{2} \mathbf{H}^{+}$ & 1.62 & $\mathrm{H}_{2} \mathrm{CNO}$ \\
\hline 15 & $\mathbf{N H}^{+}$ & 1.45 & $\mathrm{HC} 2 \mathrm{CHO}$ \\
& & 30.72 & multi-fragmentation \\
\hline 14 & $\mathbf{N}^{+}$ & 4.32 & multi-fragmentation \\
\hline 13 & $\mathbf{C H}^{+}$ & 1.30 & multi-fragmentation \\
\hline 12 & $\mathbf{C}^{+}$ & 2.60 & $\mathrm{C}_{3} \mathrm{H}_{2} \mathrm{NO} ;$ multi-fragmentation \\
\hline 1 & $\mathbf{H}^{+}$ & & \\
\hline
\end{tabular}

\subsection{Ion yield curves}

Figure 3 presents the normalized total ion yield of isoxazole measured in the photon energy range of 9.9-10.5 eV. As seen in Figure 3, the TIY reveals small steps, where the ion intensity increases and which could be due to the opening of new ionization channels. The TIY was differentiated to extract the underlying thresholds; the result is displayed as a red curve in Figure 3. In order to interpret the peaks in the differentiated TIY, Figure 3 shows for comparison the threshold photoelectron spectrum (TPES) of isoxazole measured in the same photon energy range [13]. To facilitate the comparison, the TPES was shifted by about 0.006 $\mathrm{eV}$ toward lower energies and scaled to display similar peak heights at the maximum with the differentiated TIY. The differentiated TIY is found to reproduce accurately the major peaks in the threshold photoelectron spectrum. Dampc et al. [13] established that those peaks correspond to the vibrational progression of the $3 a "\left(\pi_{3}\right){ }^{2} \mathrm{~A}$ " ionic state. The strongest peak at $9.97 \mathrm{eV}$ corresponds to the $0-0$ transition, which is followed by five vibrational series [13]. The first vibrational series was assigned to $v_{17}$ or $v_{18}$, and it consists of four excited vibrational levels separated by $68 \mathrm{meV}$ [13]. The next four vibrational series were identified as $v_{16}(99 \mathrm{meV}), v_{7}(147 \mathrm{meV}), v_{6}(171 \mathrm{meV})$, and $v_{5}(181 \mathrm{meV})$ [13]. They have very short 
vibrational progressions consisting of only one or two excited vibrational levels. Taking this into account, we can assign some peaks to particular vibrational transitions. Thus, the intense peaks lying at 10.04 and $10.10 \mathrm{eV}$ correspond to the excitation to the first and second vibrational levels of $v_{17(18)}$. The small peak at $10.07 \mathrm{eV}$ correlates with the first excited vibrational level of $v_{16}$. The broad structure with maximum lying at $10.15 \mathrm{eV}$ consists of three peaks resultant from the transitions from the first excited vibrational states of $v_{7}, v_{6}$, and $v_{5}$. The structures lying at higher energies are likely composed of overlapping peaks occurring due to excitation to vibrational levels of two combination series, namely, $v_{6}+v_{17(18)}$ (235 $\mathrm{meV})$ and $v_{5}+v_{17(18)}(247 \mathrm{meV})[13]$.

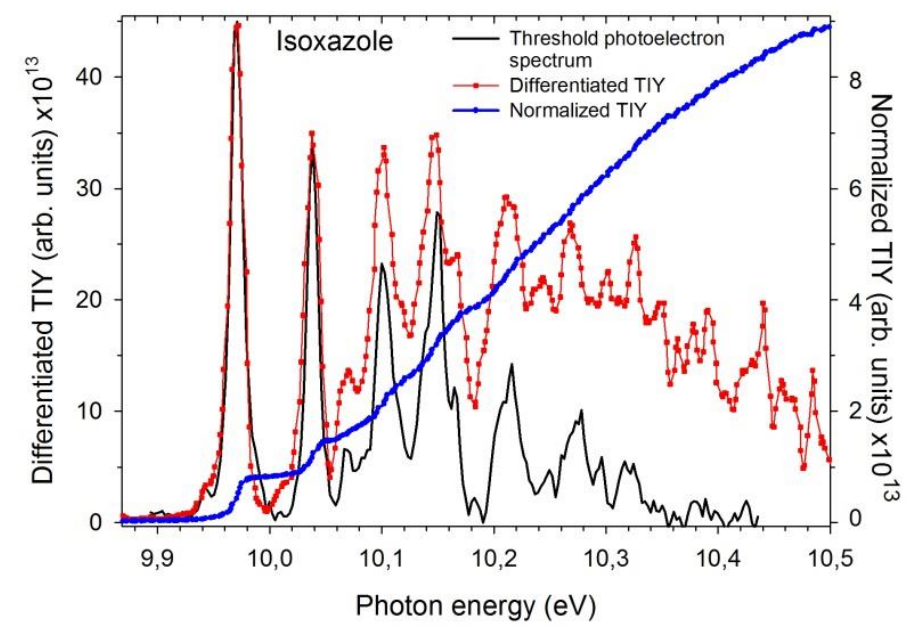

Figure 3. The blue curve shows the total ion yield (TIY) of isoxazole after normalization to the photon flux. Red points represent the differentiated TIY. The threshold photoelectron spectrum of isoxazole (black line) [13] is shown for comparison.

Figure $4 \mathrm{a}$ presents the normalized total ion yield of isoxazole measured in the whole photon energy range of $9.8-32 \mathrm{eV}$. The partial ion yields of the cations identified in Figure 2 are reported in Figures $4 b-7$. The production of the parent cation of isoxazole is dominant in the entire photon energy range studied here. The $\mathrm{m} / \mathrm{z}=40$ and 68 cations also have high relative intensities. As seen in Figures 4-7, the yields have the shapes of two broad bands with superimposed weak structures, which are most clearly seen in TIY and the $\mathrm{m} / \mathrm{z}=68-70$ 
curves. For lighter fragments that start arising at higher energies, the intensity of the first band is suppressed. The profiles of TIY and the cation yields can give us further information on the fragmentation pathways of the isoxazole molecules when we compare them to the threshold photoelectron spectra of the isoxazole molecules in the VUV region [10], [11], [12], [13]. In particular, the newest high resolution spectra measured by Dampc et al. [13] exhibit eight photoelectron bands, plus some other spectral features corresponding to the shake-up states. The energies of the observed threshold photoelectron structures are listed in Table 2 and given with vertical bars in Figure 4a. There are apparent steps or shoulders in the cation yield curves at energies close to the features specified in the threshold photoelectron spectrum. Therefore, the inflection at 9.9-10.9 eV is assigned to the $3 \mathrm{a} "\left(\pi_{3}\right)$ photoionization and its vibrational progression (as already demonstrated in Figure 3); that at $11.2 \mathrm{eV}$ to the $2 \mathrm{a} "\left(\pi_{2}\right)$ photoionization; the band at $\sim 11.3-13.5 \mathrm{eV}$ can be assigned to the vibrational progressions of the $2 \mathrm{a}^{\prime \prime}\left(\pi_{2}\right)$ and $15 \mathrm{a}^{\prime}\left(\mathrm{LP}_{\mathrm{n}}\right)$ states; the peak at $14 \mathrm{eV}$ (seen in TIY and the $\mathrm{m} / \mathrm{z}=69,70$ yields as a convex on the shoulder of the highest band) corresponds to the 14a'; the bands at $\sim 15.9$ and $17.1 \mathrm{eV}$ coincide with the adiabatic energies of the $12 \mathrm{a}^{\prime}$ and $1 \mathrm{a}^{\prime \prime}\left(\pi_{1}\right)-\pi_{4}{ }^{*} \pi_{3} \pi_{2} / 11 \mathrm{a}^{\prime}\left(\pi_{1}\right)-$ $\pi_{4}{ }^{*} \pi_{2} 15 \mathrm{a}$ ' states, respectively. At higher energies, the present cationic yields become flat, and the correspondence with the TPES is no longer evident.

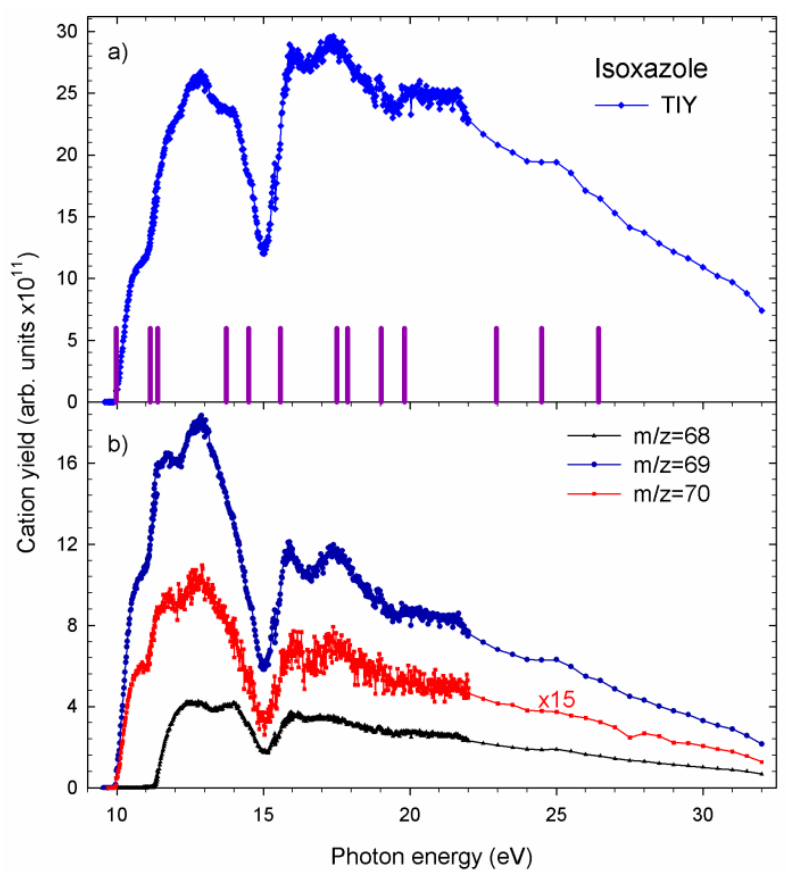


Figure 4. a) TIY obtained in the 9.8-32 eV photon energy range. The vertical bars show the energy positions of threshold photoelectron bands [13]. b) The yields of the $\mathrm{m} / \mathrm{z}=68-70$ cations obtained in the $9.8-32 \mathrm{eV}$ photon energy range.

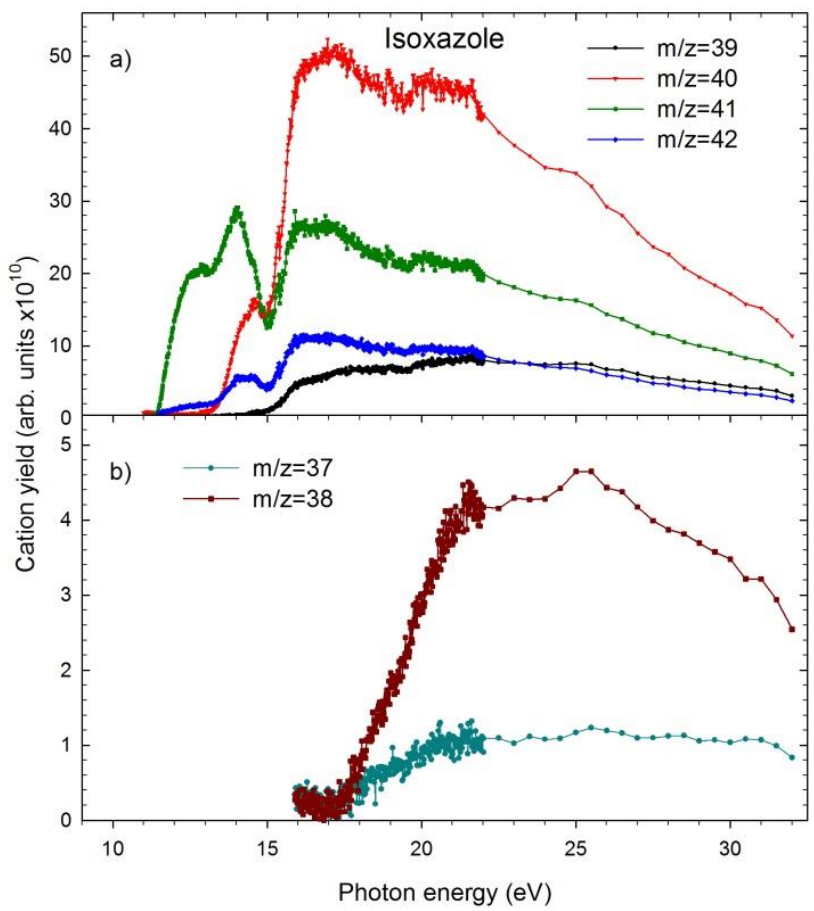

Figure 5. The cation yield curves of the $\mathrm{m} / \mathrm{z}=37-42$ cations obtained in the $11-32 \mathrm{eV}$ photon energy range.

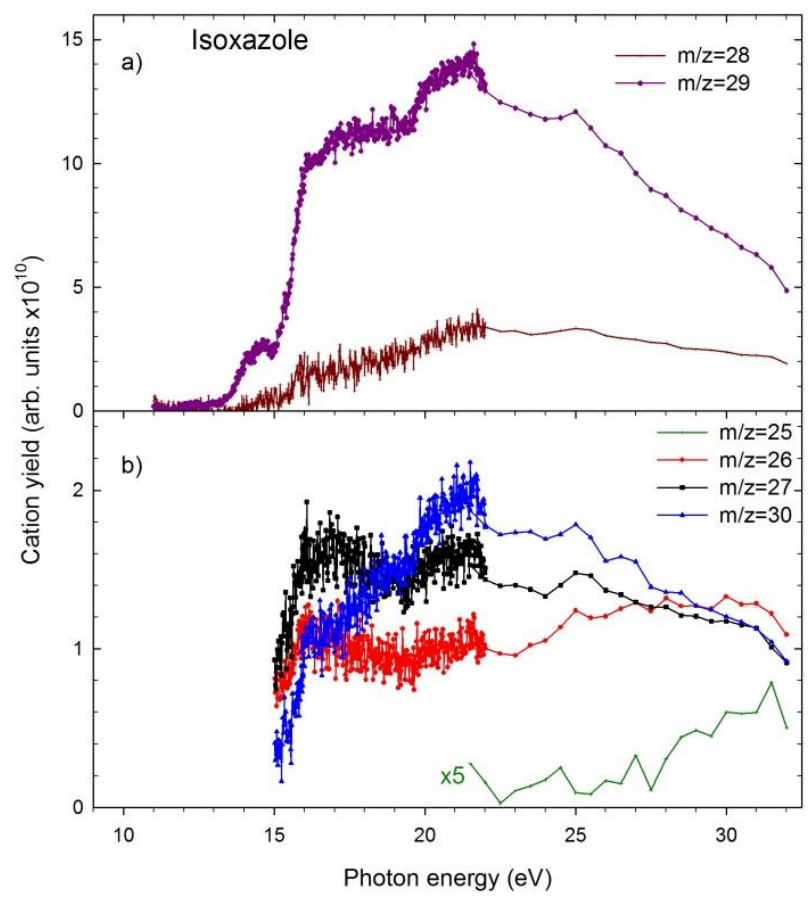


Figure 6 . The yields of the $\mathrm{m} / \mathrm{z}=25-31$ cations obtained in the $11-32 \mathrm{eV}$ photon energy range.

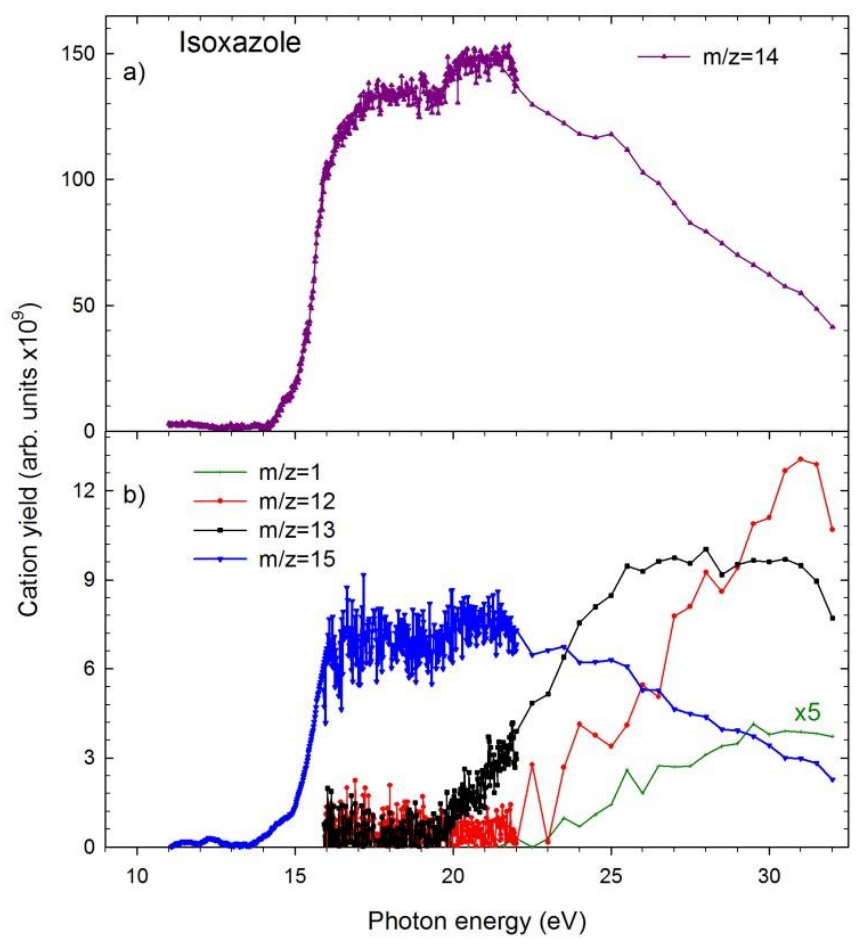

Figure 7. The yields of the $\mathrm{m} / \mathrm{z}=1$ and $12-15$ cations obtained in the $11-32 \mathrm{eV}$ photon energy range.

\begin{tabular}{|l|l|}
\hline Energy $(\mathrm{eV})$ & Assignment \\
\hline 9.976 & $3 \mathrm{a}^{\prime}\left(\pi_{3}\right)$ \\
\hline 11.132 & $2 \mathrm{a}^{\prime}\left(\pi_{2}\right)$ \\
\hline 11.40 & $15 \mathrm{a}^{\prime}\left(\mathrm{LP}_{\mathrm{n}}\right)$ \\
\hline 13.74 & $14 \mathrm{a}^{\prime}$ \\
\hline 14.49 & $13 \mathrm{a}^{\prime}$ \\
\hline 15.42 & \\
\hline 15.58 & $12 \mathrm{a}^{\prime}$ \\
\hline 15.87 & \\
\hline 17.51 & $1 \mathrm{a}^{\prime \prime}\left(\pi_{1}\right)-\pi_{4}{ }^{*} \pi_{3} \pi_{2}$ \\
\hline 17.88 & $11 \mathrm{a}^{\prime}\left(\pi_{1}\right)-\pi_{4}{ }^{*} \pi_{2} 15 \mathrm{a}^{\prime}$ \\
\hline 19.01 & $10 \mathrm{a}^{\prime}$ \\
\hline 19.81 & $9 \mathrm{a}^{\prime}$ \\
\hline 22.95 & \\
\hline
\end{tabular}


Table 2. Energies and

observed in the threshold

\begin{tabular}{|l|l|}
\hline 24.49 & \\
\hline 26.44 & \\
\hline
\end{tabular}

assignments of structures photoelectron spectrum of

isoxazole measured by Dampc et al. [13].

\subsection{Appearance energies}

The appearance energies (AEs) of the cation fragments (shown in Figure 2) were obtained from their yield curves measured in narrow energy regions around the expected positions of the AEs thresholds. The example patterns of such curves are shown in Figure 8. The respective AEs were determined by fitting the yield curves in the near-threshold regions with an exponential function $\left(E-E_{A E}\right)^{p}$, which describes the energy dependence of the dissociation cross-section. We used the fitting procedure in which the threshold energy $E_{A E}$ and the Wannier exponent $p$ were the adjustable parameters [36]. Recently this procedure was applied to the analysis of the AEs of neutral fragments occurring in photon-induced dissociation of five- and six-membered heterocyclic compounds and it was found to be efficient and reliable [21], [37], [38]. The results of curve fitting to the experimental yield curves are shown with solid red lines in Figure 8. The extracted AEs of the cations and their uncertainties (consisting 
of the uncertainty from the fitting and the uncertainty in the photon energy scale calibration) are given in Table 3. Because of the lack of photoionization studies of isoxazole, no direct comparison could be made to literature data. However, our AEs may be compared, where possible, with the data from electron impact ionization studies [14], [39]. In Table 3, the ionization energy obtained from the fitting of the total ion yield is also compared with the photoelectron spectroscopy results [11], [13].
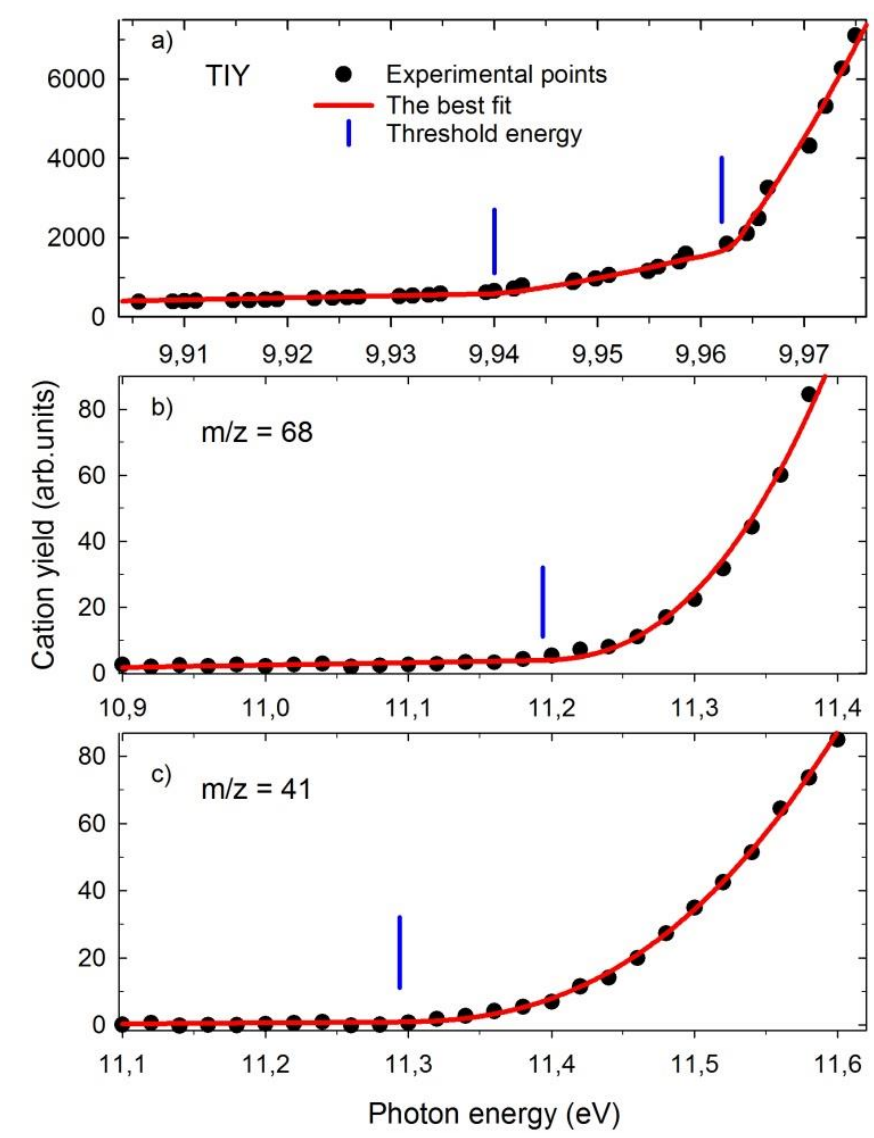

Figure 8. The yield curves measured in narrow energy regions in the vicinity of the expected AE thresholds. The solid red lines represent the best fits to the experimental data. The vertical blue bars show the energy positions of particular thresholds.

Table 3. The obtained AEs (in $\mathrm{eV}$ ) of the cations observed in the fragmentation of isoxazole molecule after absorption of VUV photons. The present AEs are compared with the results from the threshold photoelectron (TPES) or photoelectron (PES) spectroscopies, and electron impact ionization spectrometry (EI). 


\begin{tabular}{|c|c|c|c|}
\hline $\mathbf{M}(\mathbf{u})$ & Cation & $\mathbf{A E}^{\text {Present work }}$ & $\mathrm{AE}^{\text {Other works }}$ \\
\hline TIY & & $\begin{array}{l}9.94 ; \\
9.96(0.03)\end{array}$ & $\begin{array}{l}9.949^{\mathrm{a}} \\
9.976(0.003)^{\mathrm{a}} \\
9.99(0.05)^{\mathrm{b}}\end{array}$ \\
\hline 70 & ${ }^{13} \mathrm{C}^{12} \mathrm{C}_{2} \mathrm{H}_{3} \mathrm{NO}^{+}$ & $9.96(0.04)$ & \\
\hline 69 & ${ }^{12} \mathrm{C}_{3} \mathrm{H}_{3} \mathrm{NO}^{+}$ & $9.95(0.04)$ & $9.93(0.05)^{\mathrm{c}}$ \\
\hline 68 & $\mathrm{C}_{3} \mathrm{H}_{2} \mathrm{NO}^{+}$ & $11.19(0.05)$ & $11.24(0.05)^{\mathrm{c}}$ \\
\hline 42 & $\mathrm{C}_{2} \mathrm{H}_{2} \mathrm{O}^{+}$ & $12.97(0.07)$ & $12.24(0.05)^{\mathrm{c}}$ \\
\hline 41 & $\mathrm{C}_{2} \mathrm{H}_{3} \mathrm{~N}^{+}$ & $11.29(0.07)$ & $\begin{array}{l}11.80(0.05)^{\mathrm{c}} \\
11.34(0.05)^{\mathrm{d}}\end{array}$ \\
\hline 40 & $\mathrm{C}_{2} \mathrm{H}_{2} \mathrm{~N}^{+}$ & $13.14(0.07)$ & $13.34(0.05)^{\mathrm{c}}$ \\
\hline 39 & $\mathrm{C}_{2} \mathrm{HN}^{+}$ & $13.90(0.15)$ & \\
\hline 38 & $\mathrm{C}_{3} \mathrm{H}_{2}{ }^{+}$ & $17.40(0.15)$ & \\
\hline 37 & $\mathrm{C}_{3} \mathrm{H}^{+}$ & $17.25(0.15)$ & \\
\hline 29 & $\mathrm{CHO}^{+}$ & $13.21(0.10)$ & $13.62(0.05)^{\mathrm{c}}$ \\
\hline 28 & $\mathrm{CO}^{+}$ & $13.46(0.15)$ & \\
\hline 25 & $\mathrm{C}_{2} \mathrm{H}^{+}$ & $26.25(0.50)$ & \\
\hline 15 & $\mathbf{N H}^{+}$ & $13.57(0.10)$ & \\
\hline 14 & $\mathbf{N}^{+}$ & $14.09(0.10)$ & \\
\hline 13 & $\mathbf{C H}^{+}$ & $19.24(0.15)$ & \\
\hline 12 & $\mathrm{C}^{+}$ & $22.30(0.50)$ & \\
\hline 1 & $\mathbf{H}^{+}$ & $22.40(0.50)$ & \\
\hline
\end{tabular}

${ }^{\mathrm{a}}$ TPES [13]; ${ }^{\mathrm{b}} \mathrm{PES}[11] ;{ }^{\mathrm{c}} \mathrm{EI}[14] ;{ }^{\mathrm{d}} \mathrm{EI}[39]$.

\subsection{Fragmentation channels}

\subsubsection{Fragments with $\mathrm{m} / \mathrm{z}=68-70$}

This group of the fragments is formed by the parent cations $\mathrm{m} / \mathrm{z}=69,70$ and by the ionic fragment, $\mathrm{m} / \mathrm{z}=68$, formed by single dehydrogenation of the isoxazole parent cation. The most intense peak at $\mathrm{m} / \mathrm{z}=69$ in the mass spectrum (Figure 2) corresponds to the stable $\mathrm{C}_{3} \mathrm{H}_{3} \mathrm{NO}^{+}$cation, while the one at $70 \mathrm{u}$ is a composition of its ${ }^{13} \mathrm{C}^{12} \mathrm{C}_{2} \mathrm{H}_{3} \mathrm{NO}^{+}$/ $\mathrm{C}_{3}{ }^{2} \mathrm{HH}_{2} \mathrm{NO}^{+} / \mathrm{C}_{3} \mathrm{H}_{3}{ }^{15} \mathrm{NO}^{+} / \mathrm{C}_{3} \mathrm{H}_{3} \mathrm{~N}^{17} \mathrm{O}^{+}$isotopes. The measured relative intensity of the $\mathrm{m} / \mathrm{z}=70$ isotope peak is $3.76 \%$ of the intensity of the $\mathrm{C}_{3} \mathrm{H}_{3} \mathrm{NO}^{+}$peak, which is in agreement with the 
theoretical calculations $(3.79 \%)$ performed taking into consideration the natural abundances of the ${ }^{2} \mathrm{H}(0.015 \%),{ }^{13} \mathrm{C}(1.1 \%),{ }^{15} \mathrm{~N}(0.4 \%)$, and ${ }^{17} \mathrm{O}(0.038 \%)$ heavier isotopes.

Because the ionization energy was obtained from fittings to the TIY and the yields of both the $\mathrm{m} / \mathrm{z}=69$ and 70 cations (Table 3 ) independently, we calculated a weighted mean value of these results. This value was found to be $9.96(0.02) \mathrm{eV}$ and is in excellent agreement with earlier spectroscopic results of the ionization energy (IE) [11], [13], [14]. Since the lowest $\mathrm{AE}$ of the cation fragments is $11.19 \mathrm{eV}$ (Table 3), the stable parent cations are produced in the ionization of isoxazole into the $3 \mathrm{a} "\left(\pi_{3}\right)$ state. The calculations performed by Bouchoux et al. [14] showed that ionization of isoxazole involves isomerization of the parent cation and proceeds through ring-opening by cleavage of the $\mathrm{N}-\mathrm{O}$ bond. This is also an established initial step for neutral isoxazole dissociation [17], [18], [19], [20], [22], [23], [24], [25], [27].

In Figure 8a, a low-intensity threshold is seen at $9.94 \mathrm{eV}$ in the TIY curve, which is 22 meV below the ionization energy. It is a spectroscopic evidence of the production of very low energy electrons from highly excited Rydberg states that converge to the first ionization potential. A similar structure was observed on the low-energy side of the $0-0$ transition of the $3 \mathrm{a}$ " $\left(\pi_{3}\right)$ band (27 meV below this IE) in the threshold photoelectron spectrum of isoxazole [13]. An analogous spectroscopic feature has also been detected previously in threshold photoionization studies of simpler systems, i.e., argon [40].

The first cationic fragment with $68 \mathrm{u}$ is created by the loss of one neutral $\mathrm{H}$ atom from the parent cation into $\mathrm{C}_{3} \mathrm{H}_{2} \mathrm{NO}^{+}$. The $\mathrm{H}$ elimination is not a simple rupture, but it likely involves an isoxazole ring opening and the migration of the hydrogen atoms before fragmentation [14]. The $\mathrm{AE}$ of the $\mathrm{C}_{3} \mathrm{H}_{2} \mathrm{NO}^{+}$cation was measured to be at $11.19(0.05) \mathrm{eV}$, which agrees with the AE determined in electron impact studies of Bouchoux et al. [14]. Comparison of the corresponding cation curve with the TPES spectrum may suggest that abstraction of the $\mathrm{H}$ atom is associated with ionization of the isoxazole molecule into the $2 \mathrm{a}{ }^{\prime}\left(\pi_{2}\right)$ and $15 \mathrm{a}^{\prime}\left(\mathrm{LP}_{\mathrm{n}}\right)$ states. In particular, a single vibrational series attributed to the $\mathrm{C}-\mathrm{H}$ stretching mode in the $2 \mathrm{a}$ " $\left(\pi_{2}\right)$ band can be distinguished in the TPES spectrum [13]. 
Therefore, an electron removal from the $2 \mathrm{a} "\left(\pi_{2}\right)$ orbital would weaken the respective $\mathrm{C}-\mathrm{H}$ bond and initiate dissociation of the $\mathrm{C}_{3} \mathrm{H}_{3} \mathrm{NO}^{+}$cation. When the neutral $\mathrm{H}$ atom is removed from the isoxazole molecule, it can be created in an excited state and thus can be detected by its fluorescence. In fact, the fluorescence spectra recorded in the photodissociation of isoxazole showed strong atomic lines of hydrogen excited to the $n=3-7$ states [21]. It is of note that in the fragmentation of other five-membered heterocyclic molecules the excited $\mathrm{H}(n)$ atoms were also produced very efficiently [37], [41], [42] suggesting the importance of this fragmentation channel.

\subsubsection{Fragments with $\mathrm{m} / \mathrm{z}=37-43$}

In the $\mathrm{m} / \mathrm{z}=37-43$ region, seven peaks can be observed. The strongest peaks in this mass region are $\mathrm{m} / \mathrm{z}=40$ and 41 (see Figures 2 and 5). The cyclic structure of isoxazole implies that fragmentation processes leading to the fragments with $\mathrm{m} / \mathrm{z}=37-43$ are complex. Theoretical calculations show that the isoxazole molecule may be a subject of intense isomerization processes of the parent cation involving ring-opening and further cleavage of several bonds [14].

The most massive fragment in this region has the mass of $43 \mathrm{u}$. Here the loss of a neutral $\mathrm{CN}(\mathrm{m} / \mathrm{z}=26)$ molecule by any of the excited parent cations leads to the formation of the $\mathrm{C}_{2} \mathrm{H}_{3} \mathrm{O}^{+}$methylcarbonyl cation. With the relative intensity of $1.4 \%$ (Table 1 ), the $\mathrm{m} / \mathrm{z}=$ 43 peak is barely seen in our mass spectrum (Figure 2). However, its neutral counterpart CN was detected as one of the most prominent features in the fluorescence spectra of isoxazole [21], [26]. The cyanide molecule $\mathrm{CN}$ was also identified as one of the significant neutral fragments in the dissociation of the six-membered heterocyclic molecules containing nitrogen [43], [44]. Thus, it may be argued that the CN detachment from biomolecules, which are built on the hydrocarbon rings containing the nitrogen heteroatoms, should be one of the most important fragmentation channels in the interaction with the ionizing radiation.

The production of the $\mathrm{H}_{2} \mathrm{C}=\mathrm{C}=\mathrm{O}^{+}$(ketene) cation (mass $42 \mathrm{u}$ ) requires detachment of the HCN (hydrogen cyanide) fragment from the parent cation. The relative intensity of the 
ketene cation is only $9.1 \%$. However, ketene and hydrogen cyanide were the main products upon irradiation of isoxazole with the laser light at $\lambda=240$ and $221 \mathrm{~nm}$ [23] and $193 \mathrm{~nm}$ [24], respectively. As reported by Cao [25], the process leading to these neutrals starts with breakage of the N-O bond that occurs upon excitation to the $\mathrm{S}_{1}\left({ }^{1} \pi \pi^{*}\right)$ or $\mathrm{S}_{2}\left({ }^{1} \mathrm{n}_{\mathrm{N}} \pi^{*}\right)$ states, followed by ring-opening and a $\mathrm{C}-\mathrm{C}$ single bond cleavage to form $\mathrm{CHCHO}$ diradical and hydrogen cyanide. Finally, after a hydrogen atom migration, the $\mathrm{CHCHO}$ diradical produces ketene. The appearance of $\mathrm{C}_{2} \mathrm{H}_{2} \mathrm{O}^{+}$may also be accompanied by the simultaneous decomposition of the HCN molecule into a hydrogen atom and cyanide radical, giving further rise to the production of the $\mathrm{CN}$ fragment. The $\mathrm{AE}$ obtained for the ketene cation is equal to 12.97 (0.07) eV (Table 3), which is lower than the AE value given by Bouchoux et al. [14]. The generation of ketene can be associated with the ionization of the isoxazole molecule into the $15 \mathrm{a}^{\prime}\left(L P_{n}\right)$ state.

The fragment with the mass of $41 \mathrm{u}$ appears at the lowest energy among those with $\mathrm{m} / \mathrm{z}=37-43$. The AE of this cation was found to be $11.29(0.05) \mathrm{eV}$, in agreement with the AE value given by Buschek et al. [39] (see Table 3). However, the AE obtained with electron impact fragmentation of isoxazole [14] is $0.5 \mathrm{eV}$ higher than our result. Comparison of the $\mathrm{C}_{2} \mathrm{H}_{3} \mathrm{~N}^{+}$cation yield curve with the TPES spectrum may suggest that its appearance is associated with ionization of the isoxazole molecule into the $15 \mathrm{a}^{\prime}\left(\mathrm{LP}_{\mathrm{n}}\right)$ state. Formation of the $\mathrm{m} / \mathrm{z}=41$ fragment requires the opening of the isoxazole ring by breaking of the weakest $\mathrm{N}-\mathrm{O}$ bond, isomerization of the parent cation to form an intermediate nitrile isomer $\mathrm{N} \equiv \mathrm{CCH}_{2} \mathrm{CHO}^{+}$ with ring open geometry, hydrogen migration and cleavage of the $\mathrm{C}-\mathrm{C}$ bond, leading to the final reaction products:

$h v+\mathrm{C}_{3} \mathrm{H}_{3} \mathrm{NO} \rightarrow \mathrm{N} \equiv \mathrm{CCH}_{2} \mathrm{CHO}^{+} \rightarrow \mathrm{C}_{2} \mathrm{H}_{3} \mathrm{~N}^{+}+\mathrm{CO}$.

The $\mathrm{C}_{2} \mathrm{H}_{3} \mathrm{~N}^{+}$may be formed in two conformations of acetonitrile $\mathrm{CH}_{3} \mathrm{C} \equiv \mathrm{N}^{+}$or ketenimine $\mathrm{H}_{2} \mathrm{C}=\mathrm{C}=\mathrm{NH}^{+}$cations [14]. Nevertheless, it is challenging to establish unambiguously, which isomer is the predominant one. For instance, the analysis of the reacting configuration of 
$\mathrm{C}_{2} \mathrm{H}_{3} \mathrm{~N}^{+}$suggested its similarity to acetonitrile [14]. Neutral photodissociation studies with the use of laser light could not distinguish between those two conformations [23], [24]. A thermal decomposition study of neutral isoxazole identified acetonitrile and carbon monoxide as the major products [15], but high-pressure pulse pyrolysis produced ketenimine and CO [20]. These experimental results were rationalized by quantum chemical calculations of the fragmentation processes [17], [18], [20] which showed that the nitrile isomer is a stable intermediate separated from the initial ring conformation and the final decomposition products of acetonitrile or ketenimine by a potential energy barrier of about 3.5 and $3.1 \mathrm{eV}$, respectively. Note that Ptasińska and co-workers [27] in DEA comparative studies of isoxazole and its methylated derivatives assigned the observed fragment with the mass 41 to the $\mathrm{HC}_{2} \mathrm{O}^{-}$anion.

The most abundant fragment in this mass region corresponds to the $\mathrm{C}_{2} \mathrm{H}_{2} \mathrm{~N}^{+}$cation (mass $40 \mathrm{u}$ ). This fragment may be formed in three conformations, namely the cyanomethyl, iminoethenyl, and azirinylium cations [14]. However, analysis of the kinetic energy release and comparison with the decomposition of acetonitrile suggest that $\mathrm{C}_{2} \mathrm{H}_{2} \mathrm{~N}^{+}$is most likely generated in the form of the cyanomethyl $\mathrm{H}_{2} \mathrm{CC} \equiv \mathrm{N}^{+}$cation [14]. The corresponding neutral moiety with the mass 29 is the $\mathrm{HCO}$ radical. However, the formation of $\mathrm{CO}$ and $\mathrm{H}$ cannot be excluded suggesting the following reactions [14]:

$$
\begin{aligned}
& h v+\mathrm{C}_{3} \mathrm{H}_{3} \mathrm{NO} \rightarrow \mathrm{N} \equiv \mathrm{CCH}_{2} \mathrm{CHO}^{+} \rightarrow \mathrm{H}_{2} \mathrm{CC} \equiv \mathrm{N}^{+}+\mathrm{HCO}, \\
& h v+\mathrm{C}_{3} \mathrm{H}_{3} \mathrm{NO} \rightarrow \mathrm{N} \equiv \mathrm{CCH}_{2} \mathrm{CHO}^{+} \rightarrow \mathrm{C}_{2} \mathrm{H}_{3} \mathrm{~N}^{+}+\mathrm{CO} \rightarrow \mathrm{H}_{2} \mathrm{CC} \equiv \mathrm{N}^{+}+\mathrm{H}+\mathrm{CO}, \\
& h v+\mathrm{C}_{3} \mathrm{H}_{3} \mathrm{NO} \rightarrow \mathrm{N} \equiv \mathrm{CCH}_{2} \mathrm{CHO}^{+} \rightarrow \mathrm{N} \equiv \mathrm{CCH}_{2} \mathrm{C}=\mathrm{O}^{+}+\mathrm{H} \rightarrow \mathrm{H}_{2} \mathrm{CC} \equiv \mathrm{N}^{+}+\mathrm{H}+\mathrm{CO} .
\end{aligned}
$$

The reactions (3) and (4) are higher energy pathways and thus are less probable than twobody decomposition of $\mathrm{N} \equiv \mathrm{CCH}_{2} \mathrm{CHO}^{+}$via the reaction (2) [14]. The AE obtained for the $\mathrm{H}_{2} \mathrm{CC} \equiv \mathrm{N}^{+}$cation is equal to $13.14(0.07) \mathrm{eV}$ (Table 3) and is in accordance with the AE value given by Bouchoux et al. [14]. It matches with the ionization potential of the 14a' orbital, which is $13.74 \mathrm{eV}$. 
The further abstraction of a hydrogen atom from the $\mathrm{H}_{2} \mathrm{CC} \equiv \mathrm{N}^{+}$cation can lead to the production of the $\mathrm{HCC} \equiv \mathrm{N}^{+}$fragment with the mass $39 \mathrm{u}$. Its $\mathrm{AE}$ is $0.76 \mathrm{eV}$ higher than that of the $\mathrm{H}_{2} \mathrm{CC} \equiv \mathrm{N}^{+}$cation, which supports this assignment. Indeed, the $\mathrm{H}$ atom abstraction from $\mathrm{H}_{2} \mathrm{CC} \equiv \mathrm{N}^{+}$requires more excitation energy than reaction (2). The formation of the $\mathrm{HCC} \equiv \mathrm{N}^{+}$ cation most likely involves ionization into the $14 \mathrm{a}^{\prime}$ state, similarly to the production of $\mathrm{H}_{2} \mathrm{CC} \equiv \mathrm{N}^{+}$. The $\mathrm{m} / \mathrm{z}=39$ fragments may also be created in the fragmentation of $\mathrm{C}_{3} \mathrm{H}_{3} \mathrm{NO}^{+}$ (most likely in the form of the $\mathrm{N} \equiv \mathrm{CCH}_{2} \mathrm{CHO}^{+}$isomer) into $\mathrm{HCC} \equiv \mathrm{N}^{+}$and neutral $\mathrm{H}_{2} \mathrm{CO}$, or $\mathrm{H}_{2} / \mathrm{CO}$, or $\mathrm{H} / \mathrm{H} / \mathrm{CO}$. However, these processes require further isomerization of the open structure of the parent cation and energy-consuming multifragmentation [14], [21], [22]. The removal of the $\mathrm{NO}$ radical or successive abstraction of the $\mathrm{N}$ and $\mathrm{O}$ atoms from $\mathrm{C}_{3} \mathrm{H}_{3} \mathrm{NO}^{+}$ may additionally lead to the formation of the $\mathrm{C}_{3} \mathrm{H}_{3}{ }^{+}$fragment $(\mathrm{m} / \mathrm{z}=39)$. The production of that cation was observed, for example, in electron impact dissociative ionization of isoxazole analogs possessing one heteroatom, i.e., furan [45] and tetrahydrofuran [46] molecules, respectively. However, here these reactions seem to be unfavorable due to energetic reasons; they would require the $\mathrm{N}$ or $\mathrm{O}$ atom migration and breakage of many bonds [14], [17], [18], [19], [20], [22], [23], [24], [25]. Even if they happened, they would have a negligible contribution to the overall production of the $39 \mathrm{u}$ fragment.

Figure $5 \mathrm{~b}$ ) shows the cation yields of the 37 and $38 \mathrm{u}$ fragments. These curves have very similar shapes, but they differ from the cation yields of other fragments occurring in this mass region. In particular, both the cations appear at quite high energies, i.e., $17.40(0.15)$ and $17.25(0.15) \mathrm{eV}$, respectively, pointing to few-particle fragmentation reactions. The peaks at 37 and $38 \mathrm{u}$ are tentatively assigned to the $\mathrm{C}_{3} \mathrm{H}^{+}$and $\mathrm{C}_{3} \mathrm{H}_{2}{ }^{+}$cations, respectively. We attribute their appearance to ionization of the isoxazole molecule into the $1 \mathrm{a} "\left(\pi_{1}\right)-\pi_{4}{ }^{*} \pi_{3} \pi_{2}$ shake-up states. A recent theoretical investigation of the fragmentation channels of neutral isoxazole [47] supports an interpretation that the peaks at 37 and $38 \mathrm{u}$ can be assigned to the $\mathrm{C}_{3} \mathrm{H}^{+}$and $\mathrm{C}_{3} \mathrm{H}_{2}{ }^{+}$cations, respectively. It suggests that isoxazole molecule may follow a new fragmentation pathway in which both cations may be formed by the parent cation 
isomerization with increasing the collision energy, followed by the NO radical detachment, and successive hydrogen atoms abstractions, according to the reactions [47]:

$$
\begin{gathered}
h v+\mathrm{C}_{3} \mathrm{H}_{3} \mathrm{NO} \rightarrow \mathrm{C}_{3} \mathrm{H}_{3} \mathrm{NO}^{+} \rightarrow \mathrm{C}_{3} \mathrm{H}_{2}^{+}+\mathrm{H}+\mathrm{NO}, \\
h v+\mathrm{C}_{3} \mathrm{H}_{3} \mathrm{NO} \rightarrow \mathrm{C}_{3} \mathrm{H}_{3} \mathrm{NO}^{+} \rightarrow \mathrm{C}_{3} \mathrm{H}^{+}+\mathrm{H}_{2}+\mathrm{NO} .
\end{gathered}
$$

\subsubsection{Fragments with $\mathrm{m} / \mathrm{z}=25-30$}

The relative intensities of the cations in the 25-30 u region are lower than $21 \%$ (Table 1 ). The peaks at 28, 29, and $30 \mathrm{u}$ are assigned to carbon monoxide $\left(\mathrm{CO}^{+}\right)$, formyl radical $\left(\mathrm{HCO}^{+}\right)$, and formaldehyde $\left(\mathrm{H}_{2} \mathrm{CO}^{+}\right)$, respectively. The most intense peak in this mass region belongs to the $\mathrm{HCO}^{+}$cation produced in the reaction:

$$
h v+\mathrm{C}_{3} \mathrm{H}_{3} \mathrm{NO} \rightarrow \mathrm{N} \equiv \mathrm{CCH}_{2} \mathrm{CHO}^{+} \rightarrow \mathrm{HCO}^{+}+\mathrm{H}_{2} \mathrm{CC} \equiv \mathrm{N} .
$$

The $\mathrm{AE}$ of $13.21 \mathrm{eV}$ determined for this cation coincides within the experimental uncertainties with that of the $\mathrm{H}_{2} \mathrm{CC} \equiv \mathrm{N}^{+}$cation formed in an alternative process (2) suggesting the same intermediate state for processes (2) and (7) and disregarding of few-particle breakups similar to reactions (3) and (4). However, the difference in the peaks' intensities implies that $\mathrm{HCO}^{+}$is less likely produced than $\mathrm{H}_{2} \mathrm{CC} \equiv \mathrm{N}^{+}$.

The carbon monoxide cation is most likely released in the unimolecular decomposition of isoxazole similar to the (1) reaction:

$$
h v+\mathrm{C}_{3} \mathrm{H}_{3} \mathrm{NO} \rightarrow \mathrm{N} \equiv \mathrm{CCH}_{2} \mathrm{CHO}^{+} \rightarrow \mathrm{CO}^{+}+\mathrm{C}_{2} \mathrm{H}_{3} \mathrm{~N} .
$$

However, the $\mathrm{AE}$ of $13.46(0.15) \mathrm{eV}$ determined for the $\mathrm{CO}^{+}$cation is higher than the value obtained for $\mathrm{C}_{2} \mathrm{H}_{3} \mathrm{~N}^{+}$(see Table 3). The formation of $\mathrm{CO}^{+}$most likely involves ionization of isoxazole into the $14 \mathrm{a}^{\prime}$ state. Generally, the reactions leading to the acetonitrile/ketenimine and carbon monoxide, and to the cyanomethyl and formyl radicals were recognized as two of 
the most predominant pathways in the dissociation of ionized [14], and neutral isoxazole [15], [19], [20], [24], respectively. It is of note that similar reactions were found in the decomposition of the isoelectronic molecule furan [45], [48]. In its two key decomposition pathways, furan splits to methylacetylene (isoelectronic with acetonitrile) and carbon monoxide as well as to propargyl and formyl radicals in practically the same processes. Therefore, the production of other cations with masses 29 and 28, e.g., $\mathrm{CH}_{2} \mathrm{NH}^{+}$and $\mathrm{H}_{2} \mathrm{CN}^{+}$, can be ruled out.

The $\mathrm{m} / \mathrm{z}=27$ and $26 \mathrm{u}$ mass peaks likely correspond to the $\mathrm{HCN}^{+}$and $\mathrm{CN}^{+}$cations, respectively. This assignment is based on the fact that the analogous neutral fragments were observed in the fragmentation of neutral isoxazole. $\mathrm{HCN}$ was, for example, determined as the most abundant product in the laser-induced photodissociation of isoxazole [23], [24]. In previous pyrolytic experiments, HCN was also observed, but not as a major product [15]. Calculations demonstrated [25] that it could be obtained directly from the ring by a process very similar to the fragmentation pathway leading to the ketene loss. This process starts with the breakage of the $\mathrm{N}-\mathrm{O}$ bond followed by ring-opening and a $\mathrm{C}-\mathrm{C}$ single bond cleavage to form hydrogen cyanide and $\mathrm{CHCHO}$ diradical, which after a hydrogen migration becomes ketene. Further decomposition of the $\mathrm{HCN}^{+}$by a consecutive hydrogen atom abstraction may lead to the production of the $\mathrm{CN}^{+}$cation. As was mentioned above, the $\mathrm{CN}$ fragment was the most prominent feature in the isoxazole fluorescence spectra [21], [26].

The $\mathrm{m} / \mathrm{z}=25 \mathrm{u}$ cation, which is unambiguously assigned to $\mathrm{C}_{2} \mathrm{H}^{+}$, has its $\mathrm{AE}$ at a higher value (see Table 3), pointing to many-body fragmentation processes. The intensity of the $\mathrm{C}_{2} \mathrm{H}^{+}$cation in the mass spectrum of Figure 2 is about $1.6 \%$ of the peak with the highest intensity $\left(\mathrm{C}_{3} \mathrm{H}_{3} \mathrm{NO}^{+}\right)$.

\subsubsection{Fragments with $\mathrm{m} / \mathrm{z}=1-15$}

This mass region consists of the lightest atomic and diatomic cations. The peak with the mass of $15 \mathrm{u}$ is the fragment that originates at the lowest energy in the $\mathrm{m} / \mathrm{z}=1-15$ region. The AE of this cation was found to be $13.57(0.10) \mathrm{eV}$. The $\mathrm{m} / \mathrm{z}=15 \mathrm{u}$ mass peak most likely 
corresponds to the $\mathrm{NH}^{+}$cation. Observation of the $\mathrm{NH}^{+}$radical, which is not a structural unit of the isoxazole molecule, is experimental evidence of the hydrogen atom migration along the ring before fragmentation. The production of the corresponding neutral fragment in an excited state, $\mathrm{NH}\left(A^{3} \Pi\right)$, was recently observed in the photodissociation of neutral isoxazole [22]. Density functional and $a b$ initio quantum chemical calculations were also performed to study the mechanism of the $\mathrm{NH}$ formation [22]. They suggest a fragmentation reaction, which proceeds through ring-opening by cleavage of the weakest $\mathrm{N}-\mathrm{O}$ bond, followed by hydrogen migration from $\mathrm{C}$ to $\mathrm{N}$ that builds the $\mathrm{NH}$ diatomic fragment as terminating the open ring of isoxazole, and finally scission of the $\mathrm{C} \equiv \mathrm{N}$ bond to release the $\mathrm{NH}$ fragment [22].

The cation with mass $14 \mathrm{u}$ is the most abundant fragment in this mass region. This fragment may be created in the form of an atomic $\mathrm{N}^{+}$cation or methylene radical cation $\left(\mathrm{CH}_{2}{ }^{+}\right)$. It is difficult to establish unambiguously, which fragment is the major one. On the one hand, the $\mathrm{AE}$ of $14.09(0.10) \mathrm{eV}$ determined for the cation with mass $14 \mathrm{u}$ is only $0.52 \mathrm{eV}$ higher than the value obtained for the $\mathrm{NH}^{+}$cation, which may suggest that some fraction of ionized nitrogen may arise from dehydrogenation of $\mathrm{NH}^{+}$. The cation yields of the 14 and 15 $\mathrm{u}$ fragments have also very similar shapes, but they are different from the cation yields of lighter fragments occurring in this mass region. It is of note that the production of the corresponding neutral fragments in excited states, i.e., the atomic lines of nitrogen, were detected in the isoxazole fluorescence spectra [21]. On the other hand, the production of the $\mathrm{CH}_{2}{ }^{+}$radical seems to be unfavorable because it is not a structural unit of the isoxazole molecule. Its observation would be another experimental evidence of the hydrogen atom migration along the ring before fragmentation. However, its intensity is expected to be very low, similarly to $\mathrm{NH}^{+}$. The $\mathrm{CH}_{2}{ }^{+}$cation was, for example, identified among the decomposition products of the isoelectronic molecule furan [45], and its intensity was indeed very low (2.66 $\%$ at an electron energy of $100 \mathrm{eV}$ ). Nevertheless, neither the $\mathrm{CH}_{2}{ }^{+}$nor $\mathrm{CH}_{2}$ was not detected in any study of the dissociation of isoxazole. Even if the $\mathrm{CH}_{2}{ }^{+}$cations were created, they would have a minor contribution to the overall production of the $14 \mathrm{u}$ fragment. Therefore, the 
fragment with mass $14 \mathrm{u}$ likely corresponds to the $\mathrm{N}^{+}$cation which originates from the multifragmentation of the isoxazole parent cations.

The lightest cations are $\mathrm{CH}^{+}(\mathrm{m} / \mathrm{z}=13 \mathrm{u}), \mathrm{C}^{+}(\mathrm{m} / \mathrm{z}=12 \mathrm{u})$, and $\mathrm{H}^{+}(\mathrm{m} / \mathrm{z}=1 \mathrm{u})$. They have their thresholds at $19.24,22.30$ and $22.40 \mathrm{eV}$, respectively. The fact that they appear above $19 \mathrm{eV}$, i.e., at higher energies than those of most of the heavier cations (see Table 3) points to complex, energy-consuming fragmentation channels, which lead to the total disintegration of the isoxazole parent cations. The excited neutral counterparts of the $\mathrm{m} / \mathrm{z}=1-$ 13 cations were identified by their fluorescence in the photodissociation spectra [21].

\section{Summary}

The photofragmentation of isoxazole molecules that gives rise to several ionic products was studied using synchrotron radiation excitation and ion time-of-flight spectrometry combined with the photoelectron-photoion coincidence technique. Several well-resolved mass peaks were detected in the mass range 1-70 $\mathrm{u}$ and assigned to the corresponding ions. It is of note that experiments with isotopically substituted isoxazole would be needed to distinguish some of the ions. Guided by previous theoretical calculations and in conjunction with other fragmentation measurements, the photodissociation mechanisms leading to the observed fragments were suggested. All the possible reactions induced by VUV photons most likely start from the opening of the isoxazole ring through the $\mathrm{N}(2)-\mathrm{O}(1)$ bond scission, accompanied by concerted isomerization of the parent cation, and continue by further fragmentation of the formed nitrile isomer $\mathrm{N} \equiv \mathrm{CCH} 2 \mathrm{HC}=\mathrm{O}^{+}$cation with the increase of the photon energy. The total ion yield of isoxazole and the cation yield curves were measured as functions of the incident photon energy to recognize the further evolution of the underlying photodissociation mechanisms. The AEs of the parent cations and most of the cationic fragments were determined from these curves and compared with the earlier electron impact measurements. The majority of these AEs has not been reported previously. The total and parent ion yield curves show that the ionization starts at the energy of $9.96(0.02) \mathrm{eV}$. As seen in Figures 4-7, the reaction leading to the production of the $\mathrm{C}_{3} \mathrm{H}_{3} \mathrm{NO}^{+}$is dominant in the 
whole photon energy range investigated here. Apart from the parent ion formation, three major two-body dissociative processes were distinguished. Below $15 \mathrm{eV}$, the photodissociation is governed by the production of the $\mathrm{C}_{3} \mathrm{H}_{2} \mathrm{NO}^{+}$(formed by the loss of an $\mathrm{H}$ atom) and $\mathrm{C}_{2} \mathrm{H}_{3} \mathrm{~N}^{+}$(resulting from the loss of the $\mathrm{CO}$ molecule). However, above $15 \mathrm{eV}$, the $\mathrm{H}_{2} \mathrm{CC} \equiv \mathrm{N}^{+}+\mathrm{HCO}$ fragmentation channel starts dominating over the other dissociation processes. Present investigations also demonstrate the existence of five less important twobody dissociative processes that lead to the formation of the $\mathrm{HCO}^{+}, \mathrm{C}_{2} \mathrm{H}_{2} \mathrm{O}^{+}, \mathrm{C}_{2} \mathrm{HN}^{+}, \mathrm{CO}^{+}$, and $\mathrm{C}_{3} \mathrm{H}_{2}^{+}$cations, as well as the identification of several species that originate from multifragmentation processes.

\section{Conflicts of interest}

There are no conflicts of interest to declare.

\section{Acknowledgments}

We are grateful to the Elettra-Sincrotrone Trieste for providing beamtime no. 20165364. Staying of TJW in Elettra was in part financially supported by COST Action CM1204 XLIC (COST-STSM-CM1204-36527). The assistance of the staff of the Sincrotrone Trieste is also gratefully acknowledged. We are also grateful to Dr M. Dampc for sending the threshold photoelectron spectrum of isoxazole in digital form.

\section{References}

[1] T. Schlathölter, F. Alvarado, S. Bari, R. Hoekstra, Ion-Induced Ionization and Fragmentation of DNA Building Blocks, Phys. Scr. 73 (2006) C113-C117.

[2] M. A. Huels, B. Boudaïfa, P. Cloutier, D. Hunting, L. Sanche, Single, double, and multiple double-strand breaks induced in DNA by 3- 100 eV electrons, J. Am. Chem. Soc. 125 (2003) 4467-4477.

[3] T. Schlathölter, R. Hoekstra, R. Morgenstern, Charge Driven Fragmentation of Biologically Relevant Molecules, Int. J. Mass Spectrom. 233 (2004) 173-179. 
[4] I. Kyriakou, M. Šefl, V. Nourry, and S. Incerti, The impact of new Geant4-DNA crosssection models on electron track structure simulations in liquid water, J. Appl. Phys. 119(2016) 194902.

[5] A. Traore, L. Ellis-Gibbings, A. Verkhovtsev, K. Krupa, A. Muñoz, F.Blanco, G. García, Induced molecular dissociations as a radiation damage descriptor (Nanodosimetry), J. Phys.: Conf. Ser. 635 (2015) 072068.

[6] C. Lamberth, Oxazole and Isoxazole Chemistry in Crop Protection, J Heterocycl. Chem. 54 (2017) 2974.

[7] N. Agrawal, P. Mishra, The synthetic and therapeutic expedition of isoxazole and its analogs, Med. Chem. Res. 27 (2018) 1309-1344.

[8] Jie Zhu, Jun Mo, Hong-zhi Lin, Yao Chen, Hao-peng Sun, The recent progress of isoxazole in medicinal chemistry, Bioorg. Med. Chem. 26 (2018) 3065.

[9] M. Zimecki, U. Bąchor, M. Mączyński, Isoxazole Derivatives as Regulators of Immune Functions, Molecules 23 (2018) 2724.

[10] I.C. Walker, M.H. Palmer, J. Delwiche, S.V. Hoffmann, P. Limao Viera, N.J. Mason, M.F. Guest, M.-J. Hubin-Franskin, J. Heinesch, A. Giuliani, The electronic states of isoxazole studied by VUV absorption, electron energy-loss spectroscopies, and ab initio multi-reference configuration interaction calculations, Chem. Phys. 297 (2004) 289.

[11] A.D. Baker, D. Betteridge, N. R. Kemp, R. E. Kirby, Application of photoelectron spectrometry to pesticide analysis. Photoelectron spectra of five-membered heterocycles and related molecules, Anal. Chem. 42 (1970) 1064.

[12] M.H. Palmer, R.H. Findlay, R.G. Egdell, The electronic structure of heteroaromatic molecules; ab initio calculations and photoelectron spectra for the isomeric-oxazoles and some -oxadiazoles, J. Mol. Struct. 40 (1977) 191.

[13] M. Dampc, B. Mielewska, M. R. F. Siggel-King, G. C. King, B. Sivaraman, S. Ptasińska, N. Mason, M. Zubek, Threshold photoelectron studies of isoxazole over the energy range 9.9-30 eV. Chem. Phys. 367 (2010) 75-79. 
[14] G. Bouchoux, Y. Hoppilliard, Fragmentation mechanisms of isoxazole, Org. Mass Spectrom. 16 (1981) 459.

[15] A. Lifshitz, D. Wohlfeiler, Thermal-Decomposition of Isoxazole -experimental and Modeling Study, J. Phys. Chem. 96 (1992) 4505-4515.

[16] G. I. Yranzo and E. L. Moyano, Flash Vacuum Pyrolysis of Isoxazoles, Pyrazoles and Related Compounds, Curr. Org. Chem. 8 (2004) 1071.

[17] K. Okada and K. Saito, Reaction-path dynamics study of competing channels in the thermal unimolecular decomposition of isoxazole, J. Phys. Chem. 100 (1996) 9365.

[18] J. Higgins, X. Zhou, and R. Liu, Theoretical study of thermal decomposition mechanisms of isoxazole. J. Phys. Chem. A 101 (1997) 7231.

[19] G. E. Davico, Theoretical study of the thermal isomerization of isoxazole and 5methylisoxazole, J. Phys. Org. Chem. 18 (2005) 434.

[20] C. M. Nunes, I. Reva, T. M. V. D. Pinho e Melo, R. Fausto, T. Šolomek, and T. Bally, The Pyrolysis of Isoxazole Revisited: A New Primary Product and the Pivotal Role of the Vinylnitrene, A Low-Temperature Matrix Isolation and Computational Study. J. Am. Chem. Soc. 133 (2011) 18911.

[21] T. J. Wasowicz, A. Kivimäki, M. Coreno, M. Zubek, Superexcited states in the vacuumultraviolet photofragmentation of isoxazole molecules, J. Phys. B: At. Mol. Opt. Phys. 45 (2012) 205103.

[22] T. J. Wasowicz, I. Dąbkowska, A. Kivimäki, M. Coreno, M. Zubek, Hydrogen migration in formation of $\mathrm{NH}(\mathrm{A} 3 \Pi)$ radicals via superexcited states in photodissociation of isoxazole molecules, J. Chem. Phys. 141 (2014) 064301.

[23] C. M. Nunes, I. Reva, T. M. V. D. Pinho e Melo, R. Fausto, UV-Laser Photochemistry of Isoxazole Isolated in a Low-Temperature Matrix, J. Org. Chem. 77 (2012) 8723-8732.

[24] N. Dias, B. Joalland, N. M. Ariyasingha, A. G. Suits, B. M. Broderick, Direct versus Indirect Photodissociation of Isoxazole from Product Branching: A Chirped-Pulse Fourier Transform mm-Wave Spectroscopy/Pulsed Uniform Flow Investigation, J. Phys. Chem. A 122 (2018) 7523-7531. 
[25] J. Cao, Photoinduced reactions of both 2-formyl-2H-azirine and isoxazole: A theoretical study based on electronic structure calculations and nonadiabatic dynamics simulations, J. Chem. Phys.142 (2015) 244302.

[26] I. Linert, I. Lachowicz, T. J. Wasowicz, M. Zubek, Fragmentation of isoxazole molecules by electron impact in the energy range 10-85 eV, Chem. Phys. Lett. 498 (2010) 27.

[27] Z. Li, I. Carmichael, S. Ptasińska, Dissociative electron attachment induced ring-opening in five-membered heterocyclic compounds, Phys. Chem. Chem. Phys. 20 (2018) 18271-18278.

[28] A. Kivimäki, A. Sankari, J. A. Kettunen, C. Stråhlman, J. Álvarez Ruiz, R. Richter, Field ionization of high-Rydberg fragments produced after inner-shell photoexcitation and photoionization of the methane molecule, J. Chem. Phys. 143 (2015) 114305.

[29] A. Derossi, F. Lama, M. Piacentini, T. Prosperi, N. Zema, High flux and high resolution beamline for elliptically polarized radiation in the vacuum ultraviolet and soft $\mathrm{x}$-ray regions, Rev. Sci. Instrum. 66 (1995) 1718.

[30] A. Kivimäki, J. Álvarez-Ruiz, R. Sergo, R. Richter, Production of excited H atoms at the C 1s edge of the methane molecule studied by VUV-photon-photoion and metastablefragment-photoion coincidence experiments, Phys. Rev. A 88 (2013) 043412.

[31] A. Kivimäki, C. Stråhlman, T. J. Wasowicz, J. A. Kettunen, R. Richter, Yields and Timeof-Flight Spectra of Neutral High-Rydberg Fragments at the K Edges of the CO2 Molecule, J. Phys. Chem. A 120 (2016) 4360.

[32] J.A.R. Samson, W.C. Stolte, Precision measurements of the total photoionization crosssections of He, Ne, Ar, Kr, and Xe, J. Electr. Spec.Rel. Phen. 123 (2002) 265-276.

[33] K. Kimura, Handbook of HeI Photoelectron Spectra of Fundamental Organic Molecules, Ionization Energies, ab initio Assignments, and Valence Electron Structure for 200 Molecules, Halsted Press/Japan Societies Press, New York/Tokyo, 1981.

[34] T. Trickl, E. F. Cromwell, Y.T. Lee, A.H. Kung, State-selective ionization of nitrogen in the $\mathrm{X} 2=0$ and $\mathrm{v}=1$ states by two-color $(1+1)$ photon excitation near threshold, J. Chem. Phys. 91 (1989) 6006. 
[35] W. E. Wallace, director, "Mass Spectra" by NIST Mass Spectrometry Data Center, in NIST Chemistry WebBook, NIST Standard Reference Database Number 69, Eds. P. J. Linstrom and W.G. Mallard, National Institute of Standards and Technology, Gaithersburg MD, 20899, https://doi.org/10.18434/T4D303 , (retrieved May 8, 2019).

[36] T. Fiegele, V. Grill, S. Matt, M. Lezius, G. Hanel, M. Probst, P. Scheier, K. Becker, H. Deutsch, O. Echt, A. Stamatovic, T.D. Märk, Electron and ion high-resolution interaction studies using sector field mass spectrometry: propane a case study, Vacuum 63 (2001) 561.

[37] T. J. Wasowicz, A. Kivimäki, M. Dampc, M. Coreno, M. de Simone, M. Zubek, Photofragmentation of tetrahydrofuran molecules in the vacuum-ultraviolet region via superexcited states studied by fluorescence spectroscopy, Phys. Rev. A 83 (2011) 033411.

[38] T. J. Wasowicz, I. Dąbkowska, A. Kivimäki, M. Coreno, M. Zubek, Elimination and migration of hydrogen in the vacuum-ultraviolet photodissociation of pyridine molecules, J. Phys. B: At. Mol. Opt. Phys. 50 (2017) 015101.

[39] J.M. Buschek, J.L. Holmes, F.P. Lossing, The mass spectrometric generation of neutral ethynamine $\mathrm{HC} \equiv \mathrm{CNH} 2$ and C2H3N isomers., Org. Mass Spectrom. 21 (1986) 729.

[40] R.I. Hall, A. McConkey, K. Ellis, G. Dawber, L. Avaldi, M.A. MacDonald, G.C. King, A penetrating field electron-ion coincidence spectrometer for use in photoionization studies, Meas. Sci. Technol. 3 (1992) 316.

[41] T. J. Wasowicz, B. Pranszke, Fragmentation of Tetrahydrofuran Molecules by $\mathrm{H}^{+}, \mathrm{C}^{+}$, and $\mathrm{O}^{+}$Collisions at the Incident Energy Range of 25-1000 eV, J. Phys. Chem. A 119 (2015) 581.

[42] T. J. Wasowicz, B. Pranszke, Interactions of protons with furan molecules studied by collision-induced emission spectroscopy at the incident energy range of 50-1000 eV, Eur. Phys. J. D 70 (2016) 175. 
[43] T. J. Wasowicz, A. Kivimäki, M. Coreno, M. Zubek, Formation of $\mathrm{CN}\left(\mathrm{B}^{2} \Sigma^{+}\right)$radicals in the vacuum-ultraviolet photodissociation of pyridine and pyrimidine molecules, $\mathrm{J}$. Phys. B: At. Mol. Opt. Phys. 47 (2014) 055103.

[44] T. J. Wasowicz, B. Pranszke, Observation of the Hydrogen Migration in the CationInduced Fragmentation of the Pyridine Molecules, J. Phys. Chem. A 120 (2016) 964971.

[45] M. Dampc, I. Linert, M. Zubek, Ionization and fragmentation of furan molecules by electron collisions, J. Phys. B: At. Mol. Opt. Phys. 48 (2015) 165202.

[46] M. Dampc, E. Szymańska, B. Mielewska, M. Zubek, Ionization and ionic fragmentation of tetrahydrofuran molecules by electron collisions J. Phys. B: At. Mol. Opt. Phys. 44 (2011) 055206.

[47] M. Mróz, Investigation of the fragmentation pathways of isoxazole molecule by means of molecular methods, MSc thesis, Gdańsk (2018).

[48] E.E. Rennie, L. Cooper, C.A.F. Johnson, J.E. Parker, R.A. Mackie, L.G. Shpinkova, D.M.P. Holland, D.A. Shaw, M.A. Hayes, A study of the unimolecular decomposition of internal-energy-selected furan molecular ions by threshold-photoelectron-photoion coincidence spectroscopy, Chem. Phys. 263 (2001) 149. 